Revista Iberoamericana. Vol. LXV, Núms. 188-189, Julio-Diciembre 1999; 697-712

\title{
ESCLAVOS Y LIBRES DE COLOR, NEGROS Y MULATOS EN LA INVESTIGACIÓN Y LA HISTORIA DE COLOMBIA
}

\author{
POR \\ Aline Helg \\ University of Texas at Austin
}

\begin{abstract}
La América tropical no hubiera podido ser colonizada sin el concurso de los hombres de color que fueron traídos en calidad de esclavos. Ellos cultivaron el suelo, construyeron habitaciones, abrieron los primeros caminos, crearon la primera riqueza [...] Más aún, á esos hombres fuertes, valerosos y dotados de altas cualidades de corazón, debemos, en gran parte, nuestra independencia.
\end{abstract}

Salvador Camacho Roldán (1890)

En 1991, Colombia instituyó una nueva Constitución que es decentralizada, democrática y pluralista. Reconoce la diversidad étnica y cultural del país, protege a las minorías, y acepta la existencia de indígenas en la nación, atribuyendo dos asientos senatoriales a las comunidades indígenas que lograron conservar sus tierras, tradiciones, e idiomas desde la Conquista. Por fin, la nueva Constitución acabó con la Constitución del 1886 que durante más de un siglo obligó a los colombianos a vivir en un sistema político altamente centralizado que negaba la diversidad. Admite tácitamente que las fuerzas del regionalismo ganaron contra el centralismo y que el proceso de "blanqueamiento" de la población colombiana por el mestizaje no fue total. Sin embargo, la nueva Constitución no cuestiona la imagen de Colombia como una nación mestiza (de mezcla indígena y europea). Tampoco rompe el silencio que las élites colombianas han mantenido desde principios del siglo XIX sobre la fuerte contribución de la población de origen africano a la formación de la nación. Peor aún, el intento de algunos activistas para dar a las comunidades negras los mismos derechos a la tierra y representación política que a las comunidades indígenas fue destruido por dos delegados constitucionales, un indígena guambiano y un sociólogo marxista de la predominantemente mulata Costa Caribeña (Arocha 30).

Colombia tiene la mayor población de origen africano en las Américas después de Brasil y los Estados Unidos. Según estimados semi-oficiales, entre los 35 millones de habitantes con que cuenta Colombia hoy - haciendo del país el cuarto más poblado de América Latina - el 55\% son mestizos, el 20\% blancos, el $2 \%$ indígenas, el $6 \%$ negros y el $17 \%$ mulatos. En otras palabras, de cada cuatro colombianos uno es de "pura" o parcial ascendencia africana.

Apenas en el verano del 1993, como resultado de demostraciones populares y propaganda política, los negros colombianos empezaron a ser reconocidos, a través de la 
Ley 70 de Negritudes. Esta ley reconoce el derecho a la propiedad de la tierra comunitaria ancestral de las comunidades negras de la costa del Océano Pacífico y protege su identidad cultural. Además otorga a estas comunidades dos asientos especiales en la Cámara de Representantes. Pero no reconoce las comunidades negras del Valle del Cauca y de la Costa del Caribe. A pesar de que unos intelectuales mulatos intentaron aprovecharse de este movimiento para promover la conciencia racial de los colombianos de parcial ascendencia africana, hasta el presente han fracasado.

Aún cuando los años '90 empezaron con una legislación progresista que por fin reconoce la presencia de negros en Colombia, ésta no cuestionó la representación tradicional del país como mestizo. Tal representación proviene del hecho de que la mayoría de las imágenes de Colombia se originaron en su capital, Santa Fe de Bogotá, y en las tierras altas del centro, donde la población es predominantemente de ascendencia mixta europea e indígena y donde el fenómeno del mestizaje era ya notable en en siglo XVIII. Las fuentes demográficas coloniales contribuyeron a esta imagen porque usaron la conveniente categoría de "libres de todos los colores" para clasificar la población libre que no era blanca o indígena. Sobre esta base, varios historiadores asociaron "libres" con mestizos (por ejemplo, McFarlane 34). Sin embargo, aún cuando un poco más de la mitad de la población del virreinato de la Nueva Granada vivía en la región de la cordillera oriental a fines de la colonia, la imagen que presenta Colombia se "africaniza" considerablemente si se vuelve la mirada hacia otras regiones.

Entre los siglos XVI y XVIII, unos 120.000 esclavos africanos fueron introducidos en Colombia, siendo la mayoría Minas, Ararás, Carabalí y Congos (Colmenares, Historia 43 48-52). Influyeron profundamente sobre la composición racial y la cultura de varias regiones. A fines del siglo XVIII, aproximadamente el 20\% de los 832.500 neogranadinos oficialmente registrados vivían en la Costa del Caribe y eran en su inmensa mayoría negros, mulatos, y zambos (de ascendencia mixta africana e indígena). En las tierras altas del Sur alrededor de Pasto y Popayán así como en Antioquia, regiones donde vivía otro $20 \%$ de la población del virreinato, una importante proporción era de origen africano. En otras regiones, como el Chocó y la Costa Pacífica, ocupadas por sólo el 3\% de la población total, los negros y mulatos representaban la casi totalidad (McFarlane 32-34, 353). Por consiguiente, la Nueva Granada de fines de la colonia se definía más bien por un centro mayormente mestizo rodeado por un norte, un sur y un occidente donde los descendientes de africanos predominaban.

Esta distribución racial sigue manteniéndose hoy en día. El Caribe colombiano es la región del país con la más alta densidad poblacional de origen africano mixto; también cuenta con comunidades negras establecidas por cimarrones hace ya varios siglos. Aunque poco pobladas, las tierras bajas del Pacífico son la región más "negra" de Colombia, donde el $90 \%$ de los habitantes es de origen africano (Wade 4). Las comunidades negras y la población de ascendencia africana mixta es también numerosa en el sur, particularmente en el alto Valle del Cauca, el Valle del Patía y en la ribera del río Magdalena. Sin embargo, los colombianos zambos y mulatos raramente reconocen sus orígenes africanos y no se consideran negros. La identidad negra se encuentra casi exclusivamente entre los colombianos de origen africano "puro" y en unos enclaves negros, como el Valle del Patía y el Palenque 
de San Basilio (una antigua comunidad de cimarrones en el interior de Cartagena de Indias que logró recibir un estatuto de autonomía limitada de España a principios del siglo XVIII y cuyos descendientes mantuvieron una identidad distinta hasta hoy en día).

Después de discutir la importancia que tiene la raza en la sociedad colombiana antes y después de la independencia en 1819 , este artículo, en una primera parte, analiza brevemente el pensamiento y la investigación colombiana sobre los afro-colombianos. En su segunda parte, refuta el papel marginal que se ha dado al negro en Colombia a través de un examen de su papel en la sociedad y la economía de la colonia así como en las guerras de independencia del país.

Bajo la dominación española, la raza tenía un papel importante. Los individuos eran clasificados en categorías que indicaban su mezcla de abolengo africano, europeo e indígena. Por ejemplo, el censo de Cartagena en 1777 utilizó siete categorías: español, blanco, cuarterón, pardo, mulato, negro, zambo e indio. "Esclavo" no significaba "negro" porque muchas personas libres eran negras, y muchos esclavos criollos eran mulatos, zambos y algunos cuarterones (Helg, "The Limits"; Colmenares, Historia 277). Además, siendo la raza una construcción social que varía según la región y el tiempo, la clasificación racial era flexible y no dependía sólo del abolengo sino también del nivel de educación, del estilo de vestimenta, del lugar de residencia, del estatuto ocupacional, de la fortuna y del cónyuge, entre otros (McCaa, Schwartz y Grubessich). Pero la misma flexibilidad socioeconómica de la clasificación racial muestra su importancia en la jerarquía de la sociedad colonial. En el escalón más bajo estaba la esclava negra bozal, en el más alto el blanco español con el título de Don. Los contados negros libres acomodados raramente seguían en la categoría de "negros" porque cuestionaban el sistema, y por eso subían al escalón de los "pardos". Más que un continuo socio-racial entre los extremos, había una distinción, a menudo institucional, entre los blancos y "blancos de la tierra" (de abolengo blanco dudoso) y los de origen indígena o africano "puro" o mixto. Tal separación racial era particularmente el caso en los libros parroquiales que registraban a los blancos aparte de los libres no blancos y de los esclavos, quienes se juntaban en los libros de "Pardos y Morenos" en Cartagena y los de "Mulatos, Indios, Negros y Mestizos" en Santa Fe.

Después de la independencia, el color y la raza no dejaron de ser socialmente importantes, pero las categorías raciales perdieron paulatinamente sus funciones oficiales. Hasta la abolición de la esclavitud en 1852, las distinciones oficiales principales eran entre libre y esclavo y hombre y mujer. Representativo de este proceso, en los años 1830 los libros parroquiales de Cartagena desistieron de separar los blancos del resto de la población. De igual manera, los censos de 1825, 1835, 1843 y 1851 no indicaban la raza y sólo registraban los esclavos y los eclesiásticos en categorías separadas. El censo de 1870 que siguió a la abolición, a pesar de ser más completo por dar información ocupacional, tampoco indicaba la raza, una práctica seguida hasta el presente. El censo de 1918, en particular, abiertamente excluía las categorías raciales para evitar las tensiones entre las regiones (Lannoy y Pérez 53).

Esta misma medida preventiva muestra que la raza no desapareció como objeto de preocupación pública. Las élites colombianas se esforzaban en sacar el país de su estancamiento económico, y muchos, como en el resto de América Latina, vieron en la composición racial de su población una explicación a su falta de desarrollo. Varios 
geógrafos y ensayistas sociales organizaron expediciones para estimar el potencial humano y económico del país. La más importante de estas investigaciones fue la Comisión Corográfica, iniciada en 1849 bajo la dirección del ingeniero militar italiano Agustín Codazzi, la cual dejó un informe en tres volúmenes, centenares de ilustraciones y algunos estudios escritos por sus integrantes, en particular Manual Ancízar y Felipe Pérez. También fueron influyentes los escritos del político José María Samper, adepto de las teorías raciales de Joseph Arthur Gobineau. En una época en la cual la nueva expansión colonialista de Europa y la industrialización de los Estados Unidos eran descriptas como "triunfos de la raza blanca", la inteligentsia colombiana no veía cómo su nación podría desarrollarse con una población en su inmensa mayoría compuesta de mestizos, mulatos, indígenas y negros. Los negros e indios eran designados como los principales frenos al desarrollo. El mestizaje o la desaparición progresiva de los negros e indios "puros" dentro de la población racialmente mezclada y el proceso de blanqueamiento y "civilización" de ésta- parecía la única alternativa. Varios gobiernos trataron de atraer a inmigrantes europeos, pero fracasaron casi todos los intentos.

Combinando raza y cultura, la mayoría de los autores del siglo XIX tendían a dividir la población colombiana entre "salvajes" y "civilizados". Si la categoría de "salvaje" se reservaba para los indígenas indómitos de la periferia, la de "civilizado" se aplicaba de cierta manera a los blancos y mestizos, quienes eran percibidos como integrados en la nación por su trabajo y niveles de consumo, y de otra manera a los negros, mulatos e indigenas asimilados, a quienes se acusaba de no tener otra meta más que su mera supervivencia (Safford). Para explicar el "atraso" de los negros e indígenas, los ensayistas se concentraban en los efectos a largo plazo de la esclavitud y de la conquista y explotación de los indígenas, que supuestamente produjeron rasgos hereditarios (raciales) tales como la "pereza" entre los negros y la "estupidez" entre los indios. Según varios autores, estas características eran fortalecidas por el medio ambiente, particularmente en la Costa Pacífica y el Magdalena Bajo, donde se suponía que la naturaleza daba tantos vegetales, frutas y pescado que los negros pasaban la mayor parte de su tiempo descansando. Sin embargo, algunos escritores colombianos disentían. Entre ellos se destaca el economista Salvador Camacho Roldán, citado en el epígrafe de este artículo, quien reconocía el papel fundamental de los esclavos africanos en la colonización y el desarrollo económico del país así como en sus guerras de independencia. A pesar de que Camacho Roldán atribuía una supuesta inferioridad moral a los africanos en razón de su "estado de evolución inferior", pensaba que en una situación de igualdad ante la ley y de retribución justa de su trabajo, los negros tenían las mismas capacidades que los blancos. También veía en el mestizaje el mejor remedio contra la degeneración de los blancos endogámicos de las Américas. Añadía que:

El cruzamiento de la raza europea con la africana es una necesidad que, á mi sentir, se impone yá acá en América, y no sólo en la tropical, sino en algunos países de la zona templada (1:117).

Sin embargo, las ideas de Camacho Roldán eran excepcionales. A fines del siglo XIX los estereotipos raciales empezaron a ser integrados en "tipos regionales". Característico de esta tendencia es la Nueva Geografía de Colombia escrita por regiones naturales de 
Francisco Javier Vergara y Velasco (1901) que ofrece una tipología de la población colombiana basada en la raza, la historia y el clima. Después de enumerar las varias regiones donde "la raza de color prepondera", Vergara atribuía características deterministas al patiano, al chocoano y al caucano de origen africano.

Cuanto al costeño [del Caribe], también por lo común de color, es hablador, petulante, activo, fanfarrón, más valeroso en el Magdalena que en Bolívar y Panamá, y distinto, por lo tanto, de los blancos y mestizos de la zona, con los cuales tiene en común la indolencia, el genio alegre y amigo de las diversiones y un acento especial (874-75).

El interés de los intelectuales y políticos colombianos en la "cuestión racial" aumentó considerablemente entre los años 1910 y 1930, cuando las élites reflexionaban sobre el mejor medio de unificar la nación y fomentar el desarrollo incipiente. Un debate nacional sobre el tema fue iniciado por el médico conservador Miguel Jiménez López en 1918, quien dictó una conferencia pública sobre la supuesta degeneración física y psicológica de la "raza colombiana" en parte debida al mestizaje de los españoles con las "razas inferiores" de los indios y los africanos. Según Jiménez, sólo la inmigración masiva de europeos podría salvar la raza colombiana.

El pesimismo de Jiménez generó una serie de respuestas entre las cuales varias se concentraron en la raza y el mestizaje. Para la mayoría de los autores, "el indio" era un mayor impedimento que "el negro". Como escribía el médico liberal Luis López de Mesa (que fue ministro en los años '30) el indio era un viejo prematuro, silencioso, melancólico, y rutinario, que afortunadamente iba desapareciendo como efecto de la pobreza y del mestizaje. En contraste, el negro era un niño grande, voluptoso, aficionado a la música, el baile y la risa. Deprovisto de pasado, se integró al medio latinoamericano adoptando su idioma y religión, que mezcla con magia y supersticiones. Es vanidoso, pero también curioso, fiel y buen compañero. Según López de Mesa, tanto el indio como el negro podían "mejorarse" gracias al mestizaje con el blanco. Sin embargo, como gran parte de la intelectualidad del país, este autor excluía negros y mulatos de su visión ideal de la "raza colombiana mestiza" y denunciaba los efectos perniciosos de su supuesta alta fertilidad y de su migración de las costas hacia el centro andino de la nación: "Hoy sube, lenta e indetenible, la sangre africana por las venas de nuestros ríos hacia las venas de nuestra raza" ("Tercera conferencia"129-30). Se concluía que sólo la inmigración europea, junto con una buena educación y salud pública, podrían resolver el problema racial colombiano.

En la década del treinta hubo cierto interés arqueológico y antropológico por los indígenas, aunque mínimo en comparación con el movimiento indigenista de México, Ecuador y Perú en estos años, lo que se explica en parte por el peso demográfico marginal de los indígenas colombianos (Helg, La educación 184-94). En cuanto a los negros, no recibieron ninguna atención. Como las culturas de claro origen africano existían principalmente en los "enclaves negros" y en la periferia, el interés antropológico en la contribución africana a la cultura nacional que empezaba a manifestarse en el Brasil y Cuba no resonó en Colombia.

Los estudios sobre los afro-colombianos sólo se iniciaron en los años 1950 y se debieron sobre todo a los antropólogos. Los pioneros fueron dos estudiantes del antropólogo 
norteamericano Melville Herskovits: José Rafael Arboleda Llorente, cuya tesis de maestría consistió en una etno-historia general de los negros colombianos, y Aquiles Escalante, cuyo primer trabajo analizó la cultura de Palenque de San Basilio. En la década siguiente se unieron a ellos Rogerio Veláquez, quién escribió sobre el folklore y la música del Chocó, y Manuel Zapata Olivella, cuya obra literaria, etnográfica y política "engagée" trata de varias esferas en las cuales los negros tuvieron una influencia notable tanto en la Costa Pacífica como en el Caribe. Desde los años '70, la antropóloga colombiana Nina de Friedemann ha sido una voz poderosa denunciando la concertada "invisibilidad del negro" en la academia del país así como en la construcción de la identidad nacional. Sus numerosas publicaciones sobre la Costa Pacífica y Palenque de San Basilio, junto con los trabajos de Jaime Arocha, lanzaron un desafío a la antropología colombiana caracterizada por un enfoque exclusivo sobre las comunidades indígenas. Ambos investigadores también contribuyeron a dar más visibilidad y orgullo a los negros colombianos, así como también sirvieron como asesores y nexos en la mobilización negra que llevó a la Ley 70 de Negritudes de 1993.

En el area de los estudios sobre los negros, los historiadores colombianos fueron menos politizados que los antropólogos. Hasta hace poco, su enfoque era casi exclusivamente en la esclavitud colonial, como atestiguan los trabajos de Jorge Palacios Preciado sobre la trata negrera en Cartagena (1973) y Jaime Jaramillo Uribe, Germán Colmenares, y Hermes Tovar Pinzón sobre élites y esclavos en la sociedad y la economía de la Nueva Granada. María del Carmen Borrego Pla examinó las comunidades de cimarrones en la Costa Caribeña del siglo XVII, mientras que Margarita González analizó el proceso de manumisión en Colombia. El estudio más detallado y novedoso sobre esclavos y libres de color es la etnohistoria de las comunidades negras del Valle del Patía antes, durante y después de las guerras de independencia de Francisco Zuluaga (1993).

Por último, si se incluye a todas las disciplinas, pocas obras han examinado la población colombiana de origen africano mixto, a pesar de su diversidad y peso demográfico. Una excepción es el estudio de Virginia Gutiérrez de Pineda sobre la cultura y la estructura de la familia colombiana, el cual analiza los distintos "complejos culturales" del país, entre ellos el "complejo cultural negroide o litoral fluvio minero". A pesar de tener cierto determinismo, este estudio es el único que incluye las poblaciones de origen africano "puro" y mixto de las dos costas, del río Magdalena, del Valle del Cauca y de la zona minera antioqueña en una sola area cultural (1975). La Historia doble de la Costa en cuatro volúmenes (1979-1986), obra militante del sociólogo Orlando Fals Borda que aspiraba a fomentar la mobilización popular, analiza a lo largo de tres siglos la cultura "triétnica" y "anfibia" de las comunidades rurales de la Costa Caribeña y del Bajo Magdalena. Aunque no niega la jerarquía socio-racial de la costa, Fals adopta una perspectiva de lucha de clases que pasa por alto la raza y la etnia. Mas recientemente, algunos historiadores costeños como Gustavo Bell Lemus, Adolfo Meisel Roca y Alfonso David Múnera han estudiado la sociedad del Caribe colombiano y de Cartagena a fines de la colonia con énfasis en los libres de color. ${ }^{1}$

\footnotetext{
${ }^{1}$ Algunos investigadores extranjeros también contribuyeron al desarrollo de los estudios negros en Colombia. Se destacan entre ellos Robert West, Norman E. Whitten, Michael Taussig, Peter Wade y William F. Sharp (ver bibliografía).
} 
A pesar de eso, la escasez de estudios sobre mulatos, zambos y negros no "periféricos" contribuye a explicar el predominio de la imagen de los colombianos como mestizos, una imagen fortalecida por el hecho de que uno de los tópicos más estudiados es la guerra civil de la Violencia (1946-64) que prevaleció en las regiones centrales mestizas del país. El enfoque de la mayoría de la investigación sobre Afro-Colombia ha sido en los negros "puros" que se distinguían por ciertas retenciones culturales africanas, lo que involuntariamente robusteció la idea de su posición periférica y marginal en la nación colombiana.

En contraste, un breve análisis del impacto de los negros y mulatos en la economía, sociedad, y política colombiana hasta mediados del siglo XIX demuestra que tuvieron un papel central en el desarrollo del país, como ya lo había señalado Camacho Roldán. Los esclavos fueron esenciales en la economía de la Nueva Granada, a pesar de su peso demográfico limitado. Según el censo de 1777 , los esclavos sólo representaban el $8 \%$ de los 832.500 habitantes del virreinato (McFarlane 152). Estaban repartidos desigualmente en el territorio. De los 64.981 esclavos neogranadinos registrados, el 58\% se encontraban en las cuatro provincias de Popayán, Cartagena, Antioquia y Chocó. Además, su proporción en la población de cada provincia variaba mucho. Entre el 59\% y el $70 \%$ de los moradores de las pequeñas provincias de Barbacoas, Tumaco y Raposo, en la Costa Pacífica, eran esclavos. Siempre en esta región los esclavos constituían el $34 \%$ y el $39 \%$ de la población de las provincias de Iscuand, y Chocó, respectivamente. En las provincias occidentales del centro andino, su proporción en la población era el 19\% en Antioquia, el $21 \%$ en Popayán y el $9 \%$ en Mariquita. En las provincias norteñas de Cartagena, Santa Marta, Riohacha y Girón, variaba entre el $8 \%$ y el $12 \%$. En todas las provincias centrales y los llanos orientales, los esclavos eran menos del 6\% de la población (McFarlane 353).

La desigualdad de la repartición de los esclavos no era accidental, sino que estaba muy relacionada con la economía de la época. De hecho, la mayor parte de los productos que la colonia exportaba legalmente o de contrabando venían de las provincias con la más alta proporción de esclavos y se basaban en el trabajo esclavo: principalmente el oro, y más marginalmente el ganado y los cueros. Entre 1784 y 1793, el $91 \%$ del valor de las exportaciones legales de Cartagena consistía en metales preciosos (McFarlane 152). Aunque periférico en comparación con otras economías mineras de América Latina, el oro neogranadino pagaba la mayoría de las importaciones del virreinato, llenaba las cajas reales y fomentaba el comercio entre las regiones de Nueva Granada.

El oro era producido principalmente en las minas aluviales de las tierras bajas, calientes, húmedas y de difícil acceso de la Costa Pacífica. La mayoría de los esclavos destinados a la producción del oro eran bozales, directamente importados del Africa. Después de llegar a Cartagena, debían hacer un largo y peligroso viaje hasta las minas. Los más afortunados eran llevados en champanes (canoas en parte cubiertas por un techo) por el río Atrato. Los demás caminaban, generalmente encadenados por la mano o el cuello, con poca agua y alimento, por las tierras calientes, las montañas y cimas de los Andes y la selva tropical de la Costa Pacífica. Muchos de los que habían sobrevivido a la travesía del Atlántico morían en estas traumáticas expediciones que duraban varias semanas. Los que alcanzaban su destino final necesitaban hasta un año para recuperarse y poder ser empleados en los aluviones auríferos. Cierta proporción de los esclavos eran criollos y provenían de 
las haciendas de la Costa Caribeña y de la provincia de Popayán, cuyos dueños también poseían minas (Sharp 111-126).

Por lo general, los esclavos mineros trabajaban en cuadrillas que incluían hombres y mujeres en proporciones casi iguales. Había poca división sexual del trabajo, y hombres y mujeres trabajaban largas horas para localizar los aluviones auríferos, preparar los lavaderos de oro, lavar en batea y separar el oro del cascajo. Aunque a menudo recibían raciones básicas, el alimento era tan escaso en las zonas mineras que la mayoría de los esclavos tenían días libres para cultivar una huerta. También tenían el derecho a lavar el oro por su cuenta en su tiempo libre, lo que les permitía comprar en la tienda y en algunos casos, manumitirse (Sharp 122, 131-35). Eso no significa que la esclavitud era blanda en las minas del Litoral Pacífico, sino que los esclavos eran tan costosos y difíciles de traer y a la vez tan necesarios que, a pesar de la casi ausencia del estado colonial y de la iglesia católica en la región, los dueños de esclavos evitaban perderlos por maltrato.

El oro también se encontraba en Antioquia, centro de gran parte de la producción de la colonia a principios del siglo XVII, entonces basada en el trabajo indígena y esclavo. Después, el oro antioqueño atravesó un largo período de depresión por falta de brazos y capital, hasta la segunda mitad del siglo XVIII, cuando tuvo un nuevo auge. Un número creciente de esclavos fueron importados en la provincia para trabajar en las minas aluviales del norte. En 1777 los mineros poseían sin duda la mayoría de los 8.931 esclavos registrados en Antioquia. Paralelamente, entre el principio y el final del XVIII, la participación de Antioquia en la producción aurífera de la Nueva Granada, en comparación con la del Chocó, Popayán y Barbacoas, pasó de ser la menos a ser la más importante (Twinam 17, 40; McFarlane 79-81).

Además del trabajo minero, los hombres y las mujeres esclavos de la Nueva Granada representaban una fuerza fundamental de trabajo en las haciendas de la Costa del Caribe, de la región de Mompox y de las provincias de Popayán y Antioquia. Como los principales poseedores de minas también tenían grandes haciendas, la presencia de la esclavitud en ambas instituciones económicas no es sorprendente. También demuestra la importancia de los esclavos en la producción agrícola del virreinato. En las provincias de Cartagena, Santa Marta y en el Valle del Cauca del siglo XVIII, el número y tamaño de las haciendas que se dedicaban a la agricultura tropical (en particular la caña de azucar) y el ganado aumentó gracias al trabajo de los esclavos, junto con peones y aparceros. Cerca de Cartagena, varias grandes haciendas azucareras empleaban hasta un centenar de esclavos cada una. A pesar de que la mayoría de la caña y del ganado eran destinados a los mercados regionales, parte de las bestias y de los cueros eran exportados de contrabando hacia Jamaica (McFarlane 4546; Tovar, Hacienda 48-54). En el Valle del Cauca, las haciendas azucareras, entre otras, usaban casi exclusivamente el trabajo esclavo. Su producción de azúcar y carne servía al consumo regional y a la alimentación de los esclavos de las minas. Los esclavos de las haciendas también eran una especie de reserva de mano de obra para la minería(Colmenares, "El tránsito"; Hamnett 304). En Antioquia, la producción agrícola siguió siendo marginal, para el consumo local, y por lo general dominada por los pequeños propietarios de tierras. Pero los hacendados más importantes, quienes exportaban productos como el maíz desde el valle de Medellín hacia otras regiones, dependían del trabajo esclavo (Twinam 99). Además, los esclavos tenían un papel fundamental en la economía urbana de Cartagena y 
Mompox, en particular, donde trabajaban en el servicio doméstico, la construcción, el pequeño comercio, la artesanía y las actividades portuarias.

Desde el inicio de la esclavitud africana en la Nueva Granada, los esclavos emplearon varias estrategias para asegurar su libertad. Como resultado, los libres de color fueron rápidamente más numerosos que los esclavos en todas las regiones excepto el Litoral Pacífico. Aunque no hubo rebeliones masivas de esclavos en la colonia después del ataque y destrucción de la ciudad de Santa Marta por cimarrones en 1545, se denunciaron conspiraciones de esclavos en Cali en 1772, Medellín en 1777, Cartago en 1785 y Cartagena en 1694 y 1799. Esta última reunió esclavos haitianos, bozales y criollos así como un oficial de la artillería, todos negros, y fue denunciada por un cabo pardo. ${ }^{2}$ Se reprimieron revueltas de esclavos en Zaragoza en 1598, 1626 y 1659, en Cartagena en 1600, 1650 y 1693, en Tadó (Chocó) en 1728 y en Marinilla en 1796 (Jaramillo 1:67; Sharp 158). Algunos esclavos también trataron de participar en el Movimiento Comunero contra las reformas borbónicas en 1781. En Antioquia se difundió el rumor de que el rey de España había firmado una cédula otorgando la libertad a todos los esclavos. Algunos planearon la organización de una marcha de miles de esclavos sobre la capital de la provincia para pedir la publicación de la supuesta cédula y la "elevación" de los esclavos al estatuto de indios tributarios, pero fueron denunciados antes de lanzar la marcha. Sin embargo, es de notar que la cuestión de la esclavitud no fue agitada por los líderes del Movimiento Comunero y no figura en las capitulaciones que pusieron fin a la rebelión. Sólo un lider, el popular José Antonio Galán quien era de origen racial mixto, liberó varios esclavos que pertenecían a una mina española en el Alto Magdalena (Phelan 110-11, 171, 195).

Muy frecuentemente los hombres y las mujeres esclavos escogían huir de las minas y haciendas: algunos permanecían vagando en la proximidad de su antiguo lugar de trabajo, corriendo el riesgo de ser recapturados, mientras que otros se refugiaban en las numerosas rochelas (pequeños caseríos ilegales formados por cimarrones, libres de color pobres, fugitivos, desertores, mujeres también fugitivas o raptadas, y niños) que existían cerca de los ríos. Muchos, especialmente en el Chocó, desaparecían en la selva donde vivían con su familia en casi autarquía, aparte de los otros y del mundo de los blancos. Otros cimarrones crearon palenques en el interior de las costas del Caribe y del Pacífico, en la proximidad de los ríos Magdalena, Cauca y Nechí y hasta en el Putumayo. El aislamiento, lo áspero del terreno y la presencia de selvas en todas estas regiones facilitaron la huida de los esclavos y su supervivencia en comunidades escondidas. La mayoría de los palenques eran verdaderas sociedades alternativas con sus autoridades, defensa militar, jerarquía social, repartición del trabajo y sistema de creencias. Algunos esclavos cimarrones también se refugiaron en comunidades indígenas insumisas, particularmente en la Costa del Pacífico, donde en 1685 un movimiento cerca de Tadó fue reprimido por la ejecución de los negros y la esclavitud de los indios (Jaramillo 1:59-69; Gutiérrez Azopardo; Sharp 156-58; Taussig, 47).

Algunos esclavos no vacilaban en suicidarse o en matar a sus pequeños hijos para evitarles una vida de sufrimiento. Las mujeres también usaban el aborto y la contracepción

\footnotetext{
${ }^{2}$ Zejudo a Virrey, 9 abril, 1799, Archivo General de Indias (AGI), Sevilla, Estado 53, no. 77, f. 11;
} Mendinueta a Saavedra, 19 mayo, 1799, AGI, Estado 52, no. 76, f .6. 
(Rojas 94-99). Sin embargo, varios tendían a tener hijos y vivir en familias (Sharp 124-25). Algunas mujeres esclavas, especialmente en las ciudades donde eran más numerosas que los hombres esclavos, tenían relaciones sexuales con libres, y algunas, con sus amos o con blancos, fuera por fuerza y manipulación, o con la esperanza de mejorar su condición y obtener su manumisión o la de sus hijos nacidos de estas uniones. Sin embargo, no hay evidencia de que esta última estrategia haya sido muy utilizada o exitosa, en parte porque según la ley eran los esclavos mujeres - y no hombres- quienes transmitían el estatuto de esclavos a sus hijos (Colmenares, Historia 98-99, 111).

Además, la manumisión - lograda por la voluntad del amo o por la compra por el esclavo de su libertad—no era común en Colombia. Según Colmenares, entre 1720 y 1800 , se registraron sólo 472 manumisiones (en un promedio de seis por año) en la juridicción de Popayán, la cual incluía el Chocó y contaba una población total de unos 19.000 esclavos en 1777. Más de las dos terceras partes de estas manumisiones eran por compra por el esclavo (Colmenares, Historia 98-99). En el Chocó mismo, los códigos de esclavos no mencionaban la manumisión, pero los esclavos sabían que la ley española les daba el derecho de comprar su libertad. Algunos hombres y mujeres lograron hacerlo acumulando el oro que lavaban en sus días libres (141-43).

En resumen, la huida de los esclavos parece haber sido una de las causas principales del rápido crecimiento de la población libre de color durante el periodo colonial. A ésta se debe añadir las uniones entre hombres esclavos y mujeres libres y la alta tasa de natalidad entre los libres de color. Además, a fines del siglo XVIII, la trata negrera había disminuido dramáticamente, y en la Nueva Granada pocos esclavos fueron importados legalmente desde el Africa o las Américas después de 1790. Como pocas mujeres esclavas tenían hijos, la población esclava disminuía naturalmente. En 1843, el número de esclavos en Colombia había bajado a 26.778, mayor parte el 40\% de su nivel en 1777 (González 210). Como antes, la mayoría de esta disminución no se debía a manumisiones sino a los disturbios y la crisis económica generados por las guerras de independencia (cuando un alto número de esclavos lograron escaparse) así como también a las bajas de los ejércitos, las epidemias y el hambre que decimaron a los pobres y los esclavos en las ciudades y, en los años 1840, a la breve autorización de exportar esclavos. Cuando la esclavitud fue finalmente abolida en Colombia, el $1^{\circ}$ de enero de 1852 , sólo 16.468 hombres y mujeres seguían siendo esclavos (Jaramillo 1:224).

Como ya ha sido señalado, en el periodo colonial, la mayoría de la población neogranadina de origen africano no era esclava sino libre. Los libres de color también contribuyeron de una manera decisiva a la economía de la colonia. En ciudades como Cartagena y Mompox, de cada diez habitantes unos seis eran libres de color, quienes producían alimentos, bienes y servicios para estas ciudades. Los pequeños campesinos independientes y aparceros cultivaban frutas y vegetales en las cercanías de las ciudades; las mujeres de color transportaban y vendían los productos en los mercados locales; los artesanos negros, mulatos y zambos hacían herramientas y vestidos en pequeños talleres de familia o en fábricas empleando trabajadores libres y esclavos. Los negros y mulatos masones, carpinteros y ebanistas hacían edificios y muebles. Aún cuando algunos artesanos prosperaban, obviamente éstos nunca alcanzaban al estatuto de la élite blanca. El color de su piel y su origen africano les prohibían entrar en las profesiones liberales, el clero y muchos empleos en el ejército y la administración colonial. 
Hasta la introducción de los barcos de vapor a mediados del siglo XIX, eran negros, mulatos y zambos los que transportaban todas las mercancías, los viajeros y el correo sobre la principal arteria de Colombia, el río Magdalena, el cual vinculaba el interior del país con la Costa del Caribe y el mundo exterior. Llamados bogas, estos hombres trabajaban por equipos de unos doce sobre champanes que halaban con cuerdas y palancas río arriba y navegaban río abajo en el clima ardiente de la región (Peñas). Hombres y mujeres libres de ascendencia africana también cumplieron un papel fundamental en la producción y distribución regional de los alimentos, el algodón, el tabaco y el arroz tanto en la Costa Caribeña como en el Cauca. En la costa, este papel incrementó después de las expediciones militares lanzadas por España entre los años 1740 y 1780 para acabar con la comunidades indígenas indómitas y destruir las rochelas esparcidas en toda la región. Millares de sus moradores fueron forzosamente bautizados y reestablecidos en pueblos legales donde muchos se volvieron aparceros dependientes de los grandes terratenientes. A raíz de esto, la producción y el comercio crecieron en la región, lo que benefició a una creciente élite de hacendados, comerciantes, burócratas y eclesiásticos acaudalados, de los cuales muchos residían en Cartagena y Mompox (Meisel; Tovar, Hacienda).

Los hombres mulatos y negros fueron igualmente muy importantes en la defensa militar del virreinato contra los ataques exteriores y las rebeliones regionales y de indígenas. Formada en los años 1770 en la Costa de Caribe, la milicia disciplinada se componía en Cartagena de dos batallones, uno de blancos, otro de pardos, y de un batallón de artillería integrado por una mayoría de negros; en el resto de la provincia costeña, España creó milicias "de todos los colores", porque casi no había blancos para reclutar. Pero por miedo a una insurrección general de los negros, la Corona no quiso formar milicias de color en la Costa Pacífica, excepto en Nóvita, donde se creó una pequeña compañía de mulatos libres. España extendió el fuero militar y algunos privilegios corporativos a todos los milicianos. A pesar de que la igualdad racial no existía en el ejército, la incorporación en la milicia dio a estos hombres de color una nueva conciencia de su papel sociopolítico y un sentido de participar el mismo pie que los blancos en una corporación fundamental de la sociedad colonial (Kuethe 128; Sharp 152-53). Sin embargo, simultáneamente, los puso en una posición de poder en relación con las capas más bajas de la sociedad: los indígenas, los muy pobres y los esclavos.

Así como el papel socioeconómico de los esclavos y los libres de color ha sido subestimado en el período colonial, así también su papel en las guerras de independencia del país no ha sido adecuadamente reconocido. Sin embargo, sería un error asumir que todos los descendientes de africanos apoyaron la causa de la independencia contra España. Ciertos esclavos no fueron insensibles a la promesa de la Corona de otorgar la libertad personal a los que sirvieran en sus filas, tanto que los líderes del movimiento de la independencia tuvieron que responder haciendo la misma promesa a los que integraran sus tropas (Hamnett 309). Muchos esclavos, como propiedad de sus amos, fueron forzosamente reclutados por ambos adversarios por el medio de la confiscación y de los impuestos de guerra o como contribución voluntaria de sus amos, y llegaron a constituir una gran proporción de los soldados de primera fila, la mayoría, expuestos a morir en combate; otros fueron vendidos en el exterior para financiar la guerra. ${ }^{3}$ En cuanto a los libres de color,

${ }^{3}$ AGI, Cuba, 715; AGI, Caracas, 19. 
actuaron de acuerdo con las estructuras socio-raciales y económicas existentes. Muchos, en particular los artesanos y pobres de Cartagena y Mompox, exigieron de sus líderes blancos la proclamación de la independencia junto con la igualidad de todos los libres y formaron cuerpos militares para resistir a las tropas realistas. Como lo notaron varios observadores extranjeros, la mayoría de los soldados y muchos oficiales de los ejércitos libertadores eran negros, mulatos y zambos. Pero otros libres de ascendencia africana, como los habitantes del Valle del Patía, lucharon voluntariamente al lado de España contra la aristocracia criolla esclavista y racista que encabezaba el movimiento independiente del Cauca. Además, como las guerras se prolongaron desde 1811 hasta 1822, la población rural de color resistió cada vez más el reclutamento forzado y el pillaje en ambos ejércitos que los decimaba y arruinaba. En esta década se volvieron a formar muchos caseríos ilegales de prófugos y campesinos huyendo de la guerra.

Aunque la república trajo la igualdad ante la ley a los libres sin considerar su raza, no suprimió las diferencias raciales. Entre los descendientes de africanos, las distinciones de clase y color no cesaron y, hasta la abolición, por lo general los libres se desinteresaron de la suerte de los esclavos. Sin embargo, una vez terminadas las guerras de independencia, muchos soldados y oficiales sin oficio se quedaron en los ejércitos donde empezaron a rivalizar entre sí. Tensiones de razas y clases encontraron allí un terreno para expresarse, como lo muestran las luchas de facciones que agitaron la Costa del Caribe y el Cauca durante varias décadas. En Cartagena, en particular, el general venezuelano Mariano Montilla, un aristocrata blanco apoyado por la élite local, se oponía al general José Padilla, un mulato de origen modesto, quién en 1828 trató de mobilizar a los negros y pardos pobres de la ciudad contra Montilla. Injustamente acusado de atentar contra la vida del libertador Simón Bolívar, Padilla fue fusilado, sirviendo de escudo al verdadero líder de la conspiración antibolivariana, el general blanco Francisco de Paula Santander. ${ }^{4}$ En cuanto a los negros y mulatos del Valle del Cauca, organizaron varias intentonas que afectaron la economía de la región sin lograr disminuir el monopolio de la aristocracia criolla. Pero en una ocasión el general mulato David Peña hizo temblar a la élite de Cali, obligando a las damas conservadoras a barrer las calles (Taussig).

La república tampoco liberó inmediatamente a los esclavos. Antioquia fue la primera provincia en promulgar, en 1814, una ley "sobre la manumisión de la posteridad de los esclavos africanos y sobre los medios de redimir sucesivamente a sus padres", la cual prohibía el comercio de esclavos fuera de la provincia. En 1821 el Congreso de Cúcuta siguió este modelo y refutó la opinión de Bolívar, quién sostenía la necesidad de la libertad absoluta de los esclavos en la república. De hecho, la ley de 1821 prolongaba la esclavitud y defendía los intereses de los propietarios de esclavos: otorgaba la libertad a los hijos de esclavas nacidos a partir de 1821, pero les forzaba a servir al amo de su madre hasta los 18 años de edad; recomendaba la manumisión con indemnización de los amos sin dotar las juntas de manumisión de fondos para este fin. Sólo dos medidas beneficiaron inmediatamente a los esclavos: una otorgaba la libertad a los que habían servido en las filas del ejército; otra prohibía la compra y venta de esclavos al exterior. En realidad, la ley produjo pocas

${ }^{4}$ U.S. National Archives, Despatches from the United States Consuls in Cartagena, Colombia, marzooctubre, 1828. 
manumisiones y no paró el contrabando de esclavos. La situación de los esclavos empeoró después de la guerra civil de 1839-41, durante la cual los liberales, especialmente en las provincias del sur, habían incitado a los esclavos de hacendados conservadores a alzarse contra sus amos para arruinarlos. En 1843, después de su victoria, los conservadores relegalizaron la trata de esclavos y extendieron el concertaje forzoso de los hijos de esclavas hasta los 25 años de edad. El proceso de manumisión se aceleró sólo a fines de la década, cuando el liberalismo hizo de la emancipación una de sus banderas políticas y logró en 1851 la aprobación de la abolición de la esclavitud (González; Tovar, De una chispa 69-72).

Por último, las guerras de independencia y las rivalidades militares de las primeras décadas de la república, tanto por el tipo de liderazgo como por el modo forzado o clientelista de reclutamiento de las tropas que promovieron, imposibilitaron la formación de agrupaciones autónomas basadas en la clase y la raza, capaces de hacer contrapeso a las élites blancas. Las facciones se formaron alrededor de figuras locales, las cuales adquirían reconocimiento por su articulación sobre dirigentes regionales, quienes a su vez se identificaban con caudillos nacionales carismáticos (Fals 2:70B). Así se fueron creando los dos partidos políticos dominantes de Colombia, el liberal y el conservador, como dos entidades clientelistas opuestas que dieron la ilusión de una integración nacional desde el caserío hasta la capital de Bogotá, por encima de la pertenencia regional, de clase, de raza y de color. Los afrocolombianos integraron de preferencia el partido liberal, caracterizado por una retórica igualitaria que destacaba el papel del liberalismo en la abolición de la esclavitud. Sin embargo, al mismo tiempo los negros, mulatos y zambos seguían haciendo distinciones de color, clase y región entre sí, lo que les impedió denunciar la continuación de la discriminación racial en la república así como la promoción de la imagen de Colombia como una nación mestiza que negaba su importante contribución a la formación nacional. La misma Ley 70 de Negritudes de 1993, no se logró a raíz de la historia y condición propia de las comunidades creadas por los descendientes de esclavos africanos mineros del Litoral Pacífico, sino a raíz de la asimilación artificial de su condición y demandas a las de los indígenas. A pesar de ser un avance, esta ley muestra que todavía falta mucho para que los afro-colombianos sean reconocidos como parte integrante de Colombia.

\section{BiBLIOGRAFIA}

Arboleda, José Rafael. "The Ethnohistory of Colombian Negroes". Tesis de Maestría, Northwestern University, 1950.

Arocha Rodríguez, Jaime. "Afro-Colombia Denied". Report on the Americas 25 (febrero, 1992): 28-31.

Bell Lemus, Gustavo. Cartagena de Indias: de la colonia a la república. Bogotá: Fundación Simón y Lola Guberek, 1991.

Borrego Pla, María del Carmen. Palenques de negros en Cartagena de Indias a fines del siglo diecisiete. Sevilla: Escuela de Estudios Hispanoamericanos, 1973.

Camacho Roldán, Salvador. Notas de viaje (Colombia y Estados Unidos de América). [1890] 2 vols. Bogotá: Banco de la República, 1973.

Colmenares, Germán. "El tránsito a sociedades campesinas de dos sociedades esclavistas en la Nueva Granada, Cartagena y Popayán, 1780-1850". Huellas 29 (Barranquilla, agosto, 1990): 8-24. 
Historia económica y social de Colombia. Vol. 2, Popayán: Una sociedad esclavista, 1680-1800. Bogotá: La Carreta, 1979.

Comisión Corográfica. Jeografia fisica i política de las provincias de Nueva Granada. [1862]. 4 vols. Bogotá: Banco de la República, 1958.

Escalante, Aquiles. "Notas sobre el Palenque de San Basilio, una comunidad negra de Colombia". Divulgaciones Etnológicas 3/5 (Bogotá, 1954): 207-358.

Fals Borda, Orlando. Historia doble de la Costa, 4 vols. Bogotá: Carlos Valencia Editores, 1979-1986.

Friedemann, Nina S. de. Criele criele son. Del Pacifico negro. Bogotá: Planeta Colombiana Editorial S. A., 1989.

MaNgombe palenque: Ganaderos negros. Bogotá: Carlos Valencia Editores, 1980. y Jaime Arocha. De sol a sol. Génesis, transformación y presencia de los negros en Colombia. Bogotá: Planeta Colombiana Editorial, 1986.

González, Margarita. "El proceso de manumisión en Colombia". Cuadernos Colombianos 2 (Bogotá, 1974): 145-240.

Gutiérrez Azopardo, Ildefonso. Historia del negro en Colombia. Bogotá: Editorial Nueva América, 1980.

Gutiérrez de Pineda, Virginia. Familia y cultura en Colombia. Bogotá: Instituto Colombiano de Cultura, 1975.

Hamnett, Brian B. "Popular Insurrection and Royalist Reaction: Colombian Regions, 1810-1823". Reform and Insurrection in Bourbon New Granada and Peru. John R.

Fisher, Allan J. Kuethe, y Anthony McFarlane, eds. Baton Rouge: Louisiana State University Press, 1990. 292-326.

Helg, Aline. "The Limits of Equality: Free People of Color and Slaves during the First Independence of Cartagena, Colombia (1810-15)". Manuscrito, 1998.

La educación en Colombia, 1918-1957. Una historia social, económica y política.

Bogotá: CEREC, 1987.

Jaramillo Uribe, Jaime. Ensayos sobre historia social colombiana. 2 vols. Bogotá: Tercer Mundo Editores, 1989.

Jiménez López, Miguel. "Algunos signos de degeneración colectiva en Colombia y países similares: Memoria presentada al Tercer Congreso Médico Colombiano, 1918”. Los problemas de la raza colombiana. Miguel Jiménez López et al., eds. Bogotá: Linotipos El Espectador, 1920. 3-39.

Kuethe, Allan J. Military Reform and Society in New Granada, 1773-1808. Gainesville: The University Presses of Florida, 1978.

Lannoy, Juan L., y Gustavo Pérez. Estructuras demográficas y sociales de Colombia.

Bogotá: Oficina Internacional de Investigaciones Sociales de FERES, 1961.

López de Mesa, Luis. "Tercera conferencia". Los problemas de la raza colombiana.

Miguel Jiménez López et al., eds. Bogotá: Linotipos "El Espectador", 1920.

Introducción a la historia de la cultura en Colombia. Bogotá: s.e., 1930.

McCaa, Robert, Stuart B. Schwartz, y Arturo Grubessich. "Race and Class in Colonial Latin America: A Critique". Comparative Studies in Society and History 21 (1979): 421433. 
McFarlane, Anthony. Colombia before Independence. Economy, Society, and Politics under Bourbon Rule. Cambridge: Cambridge University Press, 1993.

Meisel Roca, Adolfo. "Esclavitud, mestizaje y haciendas en la provincia de Cartagena, 1533-1851". El Caribe colombiano. Selección de textos históricos. [1980]. Gustavo Bell Lemus, ed. Barranquilla: Editorial Uninorte, 1988. 69-139.

Múnera, Alfonso David. "Failing to Construct the Colombian Nation: Race and Class in the Andean-Caribbean Conflict, 1717-1816". Tesis doctoral, University of Connecticut, 1995.

Palacios Preciado, Jorge. La trata de negros por Cartagena de Indias (1650-1750). Tunja: Ediciones "La Rana y El Aguila", 1973.

Peñas Galindo, David Ernesto. Los bogas de Mompox: Historia del zambaje. Bogotá: Tercer Mundo Editores, 1988.

Pérez, Felipe. Jeografia fisica i política de los Estados Unidos de Colombia, escrita de orden del gobierno jeneral. 2 vols. Bogotá: Imprenta de la Nación, 1862-63.

Phelan, John Leddy. The People and the King. The Comunero Revolution in Colombia, 1781. Madison: University of Wisconsin Press, 1978.

Rojas Gómez, Roberto. "La esclavitud en Colombia". Boletín de Historia y Antigüedades 14 (Bogotá, abril, 1922): 83-108.

Safford, Frank. "Race, Integration, and Progress: Elite Attitudes and the Indian in Colombia, 1750-1870". Hispanic American Historical Review 71 (1991): 1-33.

Sharp, William Frederick. Slavery on the Spanish Frontier. The Colombian Chocó, 16801810. Norman: University of Oklahoma Press, 1976.

Taussig, Michael T. The Devil and Commodity Fetishism in South America. Chapel Hill: University of North Carolina Press, 1980.

Tovar Pinzón, Hermes. De una chispa se forma una hoguera: Esclavitud, insubordinación y liberación. Tunja: Universidad Pedagógica y Tecnológica de Colombia, 1992.

Hacienda colonial y formación social. Barcelona: Ediciones Sendai, 1988.

Twinam, Ann. Merchants and Farmers in Colonial Colombia. Austin: University of Texas Press, 1982.

Velásquez Murillo, Rogerio. "Cantares de los tres ríos". Revista Colombiana de Folclor 2(5) (Bogotá, 1960): 9-100.

"Ritos de la muerte en el alto y bajo Chocó". Revista Colombiana de Folclor 2(6) (1961): 9-74.

Vergara y Velasco, Francisco Javier. Nueva geografia de Colombia escrita por regiones naturales. 2 vols. Bogotá: Imprenta de Vapor, 1901.

Wade, Peter. Blackness and Race Mixture. The Dynamics of Racial Identity in Colombia. Baltimore: Johns Hopkins University Press, 1993.

West, Robert C. Colonial Placer Mining in Colombia. Baton Rouge: Louisiana State University Press, 1952.

Whitten, Norman E., Jr. y Nina de Friedemann. "La cultura negra del litoral ecuatoriano y colombiano: Un modelo de adaptación étnica". Revista Colombiana de Antropología 17 (1974): 75-115.

Zapata Olivella, Manuel. ;Levántate mulato! Por mi raza hablará el espíritu. Bogotá: Rei, 1990. 
Chambacú: Corral de negros. Medellín: Editorial Bedout, 1967.

Las claves mágicas de América (Raza, Clase y Cultura). Bogotá: Plaza \& Janes Editores, 1989.

Zuluaga R., Francisco U. Guerrilla y sociedad en el Patía: Una relación entre clientelismo politicoy la insurgencia social. Cali: Universidad del Valle, Facultad de Humanidades, 1993. 